\title{
An Applied Learning Activity for Health and Fitness Students to Advocate for School Playground and Gymnasium Safety
}

\author{
Brian F. Geiger ${ }^{1,2}$, Jane Roy ${ }^{1}$, Sandra K. Sims ${ }^{1}$, Jason S. Fulmore ${ }^{1,2}$ \& Karen A. Werner ${ }^{3}$ \\ ${ }^{1}$ Health and Physical Education Programs, Department of Human Studies, College of Arts and \\ Sciences, School of Education, University of Alabama at Birmingham \\ ${ }^{2}$ Center for Educational Accountability, University of Alabama at Birmingham \\ ${ }^{3}$ Oak Ridge Institute for Science and Education
}

\begin{abstract}
Playground accidents are a leading cause of injury to children at school and home. Health and physical education faculty and students from a university school of education and college of nursing collaborated with wellness team members in a public school system to complete a systematic planning process. The aim was to enhance the school health program and reduce risk of injuries. University faculty mentored health and physical education students as they developed professional competencies related to program planning and advocacy. Students identified safety hazards in 52 school/community playgrounds and 45 gymnasiums, and reported maintenance issues to reduce the risk of injuries. Teachers, parents, students and community residents can learn to assess playground and gymnasium safety, identify hazards, and plan improvements to the school health environment.
\end{abstract}

(C) 2009 Californian Journal of Health Promotion. All rights reserved.

Keywords: health promotion advocacy, playground, safety, injury prevention

\section{Introduction}

Structured and unstructured play is essential to children's healthy growth and development. Play provides opportunities to learn and to practice social, physical and relationship skills (National Program for Playground Safety [NPPS], 2006a; Vygotsky, 2002). Secondary benefits of play include increased attention to cognitive tasks and decreased restlessness in the classroom (Azar, 2002; Del Busto, 2005; KaBoom!, n.d.).

School personnel and taxpayers must provide safe facilities for supervised recess and physical education classes. State curriculum frameworks for health and physical education provide the impetus to teach safety and risk reduction at school and at home. Unfortunately, injury and death to children occur due to faulty construction, poor maintenance, and unsupervised use of playgrounds. Why should we be concerned about playground and gymnasium safety?

Children need to play in safe environments. Children residing in low-income areas face additional playground hazards due to unsafe equipment and inadequate maintenance (Cradock, Kawachi, Colditz, Hannon, Melly, Weicha, et al., 2005; Suecoff, Avner, Chou, \& Crain, 1999). It is difficult to obtain accurate estimates of annual playground injuries as there is no mandatory reporting requirement or single database. Estimates of annual emergency room visits to treat children's playground injuries range between 50,000 (U.S. Consumer Product \& Safety Commission [CPSC], 2005) and 200,000 (Frost \& Drescher, 2000). Approximately $45 \%$ are severe injuries including fractures, internal injuries, concussions, dislocations, and amputations. Of these injuries, 148,000 occur on public playgrounds in schools and community parks, 
most often falls from swings, climbers and slides. Fewer than $10 \%$ of playgrounds where injuries occurred clearly indicated appropriate ages for safe use (Frost \& Drescher, 2000). One study of 66 Atlanta child care centers found safety hazards at $84 \%$ of sites (Sacks, Holt, Holmgreen, Colwell, Jr., \& Brown, Jr., 1990). Similarly, Suecoff and colleagues (1999) identified inadequate fall zones in $81 \%$ of 186 New York City playgrounds.

Fifty-one thousand injuries occur on home playgrounds, most often on swings. Sixty percent of injuries are due to falls onto hard surfaces not in compliance with United States Product and Safety Commission (CPSC, 2005). An average of 15 children per year dies due to strangulation and falls onto hard surfaces or onto other equipment. The estimated cost to treat playground injuries in 2003 was $\$ 6.8$ billion (CDC, 2007; CPSC, n.d., a-e; Frost \& Drescher, 2000).

Faculty and students at a university school of education and a rural nursing program in a southeastern state in the U.S. collaborated with faculty, staff and parents in a public school between the years of 2004-2007. The aim of the collaboration was to enhance the school health program to reduce risk of chronic disease and injuries (Geiger, Sims, Evans, Roy, Werner, Prier, et al., 2009). The collaboration was a catalyst to enhance health and physical activity opportunities in at least two ways: develop and field test two practical instruments for students, teachers and caregivers to assess playground and gymnasium safety, and publish a Civil Rights and fitness walking trail through historic sites (Geiger \& Werner, 2009).

The focus of this manuscript is a report of a practical application of knowledge to enhance professional practice in health and physical education. Our intent was to teach undergraduate students to advocate for high-quality health promotion programs and related policies. The applied learning activity is compatible with Responsibilities II, VI, and VII and related competencies for professional Health Educators, i.e. II - Planning Health Education Strategies, Interventions and Programs; VI - Serve as a
Health Education Resource Person; VII Communicate and Advocate for Health and Health Education (NCHEC, 2008). Outcomes included university students' recognition of common safety hazards in school playgrounds and gymnasiums and strategies to reduce these.

\section{Description of Selma NEWS}

Selma Nutrition Exercise and Wellness for Students (Selma NEWS) is a pilot program implemented in a public school system in Alabama's impoverished Black Belt Region. School-level wellness teams were formed in early 2005, composed of administrators, teachers, school nurse, CNP staff, parents, community representatives, and students to guide program improvements. Health and physical education faculty and students from a university school of education provided technical assistance to select wellness team members, facilitate wellness team meetings, present professional development programs, and conduct a needs assessment. Wellness team members elected to focus on three components during the 2005-06 school year: health education, physical education and other activity programs, and nutrition services.

\section{Learning Project Development}

Before developing the applied student learning activity, wellness teams prepared digital images of playgrounds and gymnasiums in all 11 public schools. High school students and their teacher desired to provoke group discussion about correcting safety hazards in schools. As a result, wellness team members requested assistance from university health education faculty and students to systematically record safety hazards in need of correction. This was an ideal opportunity to engage health and physical education students enrolled in two courses (Health Promotion Program Planning and Evaluation, Planning and Management of Fitness Facilities) and nursing students from a local community college in an applied learning project.

The next step was to search for a low-cost and simple tool suitable for use by secondary students, teachers and caregivers. None was found after a preliminary literature review and 
queries made of health and physical education colleagues. Note that the activity described in this paper preceded publication of "America's Playground: Safety Report Card" by the National Program for Playground Safety (NPPS, 2006b). It is encouraging to note that identification of safety hazards by more than one group of researchers led to the development of checklists to improve playground safety.

Collaborators reviewed available documents about installation, use, and monitoring of playground equipment, and safe use of indoor athletic facilities to inform development of simple assessments (Frost \& Drescher, 2000; National Association for Sport and Physical Education, 2006 revised; NPPS, 2006c \& 2002; Texas State Department of Health, n.d.; CPSC, 2005, 2001, \& n.d., a-e; Suecoff, et al., 1999). One student's father is an architect employed by a municipality who suggested several reference documents reviewed by the class.

Wellness teams developed two new tools during an academic term, "Assessment of an Outdoor Elementary School Playground" containing 32 dichotomous items, and "Assessment of a School Gymnasium" containing 29 dichotomous items (Geiger, 2005a, 2005b). Draft tools were developed for public school audiences, reviewed by wellness team members, and then sent to a volunteer panel of eight experts. Experts represented the disciplines of physical education, health, early childhood education, exercise physiology, and school leadership and worked in K-12 and higher education.

Each panelist independently responded to a series of questions about draft items, including: 1) which items would you change; 2) what items should be added; \& 3) what items should be deleted? Panelists were asked to write an explanation of recommended changes. Collaborators added new items, revised items for clarity after expert review, and then planned pilot testing.

The first instrument, "Assessment of an Outdoor Elementary School Playground," contains 32 items presented with dichotomous response options $(1=$ Yes, $0=$ No), plus a section to add comments. Sample items include:

- Playground equipment is appropriate for age of children. Look for safety signs identifying ages and body size for safe use. Watch children at play to ensure they are able to use the equipment without signs of fear or falling.

- There is a minimum of 6 feet between playground equipment to reduce accidents and injuries.

- Stairways or stepladders shall have handrails or alternate means of hand support as shown in Figure 1.

The second, "Assessment of a School Gymnasium," contains 29 dichotomous items, plus a section to add comments. Sample items include:

- The space for physical activity is large enough to accommodate all students of a class moving at the same time.

- Electrical appliances (air conditioners, power outlets, switch boxes, transformers) are inaccessible to children.

- Emergency lighting system and exit signs in working order.

- General appearance is clean without trash, debris, spills, vermin, and graffiti.

- Smoke detectors and fire alarms visible and in working order.

Figure 1. Illustration of a City Park with Safe Playground Features

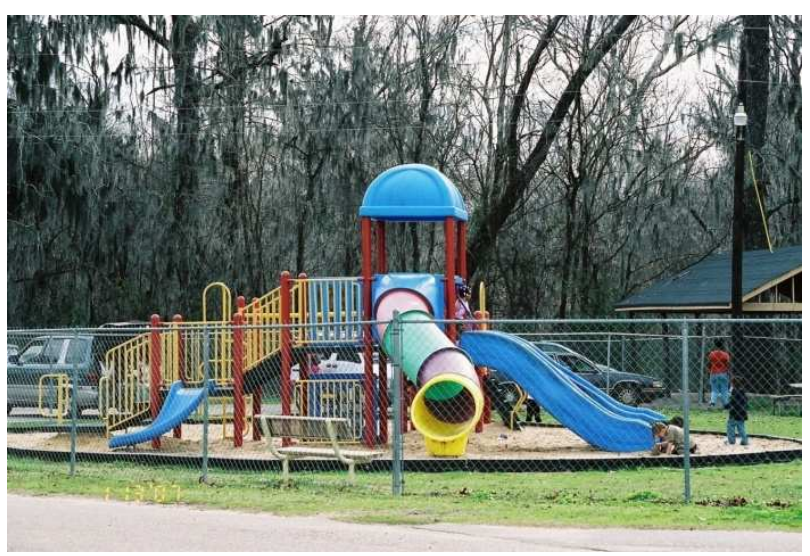

University students and faculty mentors' pilot tested both instruments during the summer and 
fall of 2005 after securing permission from school administrators or recreation directors. Students formed small groups and individually completed a minimum of five different assessments and then discussed ratings until reaching consensus. In some cases, students revisited a setting to repeat the assessment.

Faculty mentors accompanied the entire group of student raters to a community playground for a guided practice session. The purpose was to practice assessing 32 items, measure height and distance, observe children using the equipment, and record accurate data in a consistent manner. The only equipment needed to complete an assessment was a clipboard, writing tool, measuring tape and ruler. Student and faculty teams completed 153 assessments in 12 Alabama cities and 1 county following guided practice.

\section{Learning Project Outcomes}

Student pairs and faculty mentors completed a total of 153 assessments. Of these, 83 were conducted at 52 different school and community playgrounds. Playgrounds were located in seven settings: public city or county parks, church, restaurants or other businesses, elementary school, apartment or other shared residences, private day care, and YMCA. The majority of assessments $(90 \%)$ were conducted at city or county parks, church day cares, restaurants and elementary schools. Seventy assessments were conducted at 45 school and community gymnasiums located in eight settings: elementary and secondary schools, private school, college/university, church, member-only gymnasium, city or county parks/recreation, and clinical/medical. Of these settings, most assessments (62\%) were completed in elementary and secondary schools and universities.

Students chose the settings within their communities; nearly all are located within the urban counties comprising the BirminghamHoover Metropolitan Statistical Area. Each assessment required an average of 20 minutes to complete. Rating scores were entered into an Excel spreadsheet for descriptive analyses.

To assess rater consistency, faculty members calculated percentage of rater agreement across four different settings (two city parks, one restaurant playground and one church playground). Rater agreement ranged from 0.91 to 0.99 with an overall mean score of 0.94 . Data indicated strengths of the instruments and need to clarify some items. Future instrument development will include examining usefulness by setting (public school, church playground, community recreation center or park). Table 1 is a sample data sheet from a student pair for nine items on the playground assessment.

Table 1. Sample Data Sheet from a Student Pair Using Playground Assessment.

\begin{tabular}{|c|c|c|c|c|c|c|c|c|c|}
\hline Rater ID & $\begin{array}{c}\text { Min. } \\
5,000 \mathrm{sq} \\
\mathrm{ft}\end{array}$ & $\begin{array}{l}\text { Accessible } \\
\text { for disabled }\end{array}$ & $\begin{array}{c}\text { Guardrails \& } \\
\text { barriers }\end{array}$ & $\begin{array}{c}\text { Clean water } \\
\text { available }\end{array}$ & $\begin{array}{c}\text { Sand } 5 \\
\text { inches } \\
\text { deep, } \\
\text { shaded, } \\
\text { covered }\end{array}$ & $\begin{array}{c}\text { Safe } \\
\text { material } \\
\text { and depth } \\
\text { fall zones }\end{array}$ & $\begin{array}{l}\text { Equipment } \\
\text { age } \\
\text { appropriate }\end{array}$ & $\begin{array}{c}\text { Small } \\
\text { openings } \\
\text { covered }\end{array}$ & $\begin{array}{c}6 \text { feet } \\
\text { between } \\
\text { equipment }\end{array}$ \\
\hline 6 & 1 & 0 & 0 & 0 & 0 & 0 & 0 & 0 & 1 \\
\hline 7 & 1 & 0 & 0 & 0 & 0 & 0 & 0 & 0 & 1 \\
\hline
\end{tabular}




\section{School and Community Playgrounds}

Important environmental and equipmentassociated hazards were identified across playground settings. Calculated means of dichotomous data revealed the four most frequent playground hazards identified by health and physical education students across 52 sites were: Item \#5 - Sand in digging and play area is at least 5" deep, covered while not in use, enclosed in a shaded area, and replenished, as needed (mean 0.25); Item \#3 - Guardrails or protective barriers shall be provided for all elevated wheelchair-accessible ramps and platforms (mean 0.31); Item \#17 - Slides and decks are shaded from full sun (mean 0.32); \& Item \#2 - Playground is accessible to children with disabilities; at least one accessible route shall be provided from the perimeter to all play structures (mean 0.39).

Qualitative data revealed safety concerns in specific settings. Playgrounds were inaccessible to students with disabilities. Students playing on uncovered and unpainted equipment during hot summer days may suffer burn injuries. In addition, lack of a shade structure is related to ultraviolet radiation exposure. Most playgrounds lacked clean drinking water nearby outdoor play areas. Drinking fountains were often stopped up or disconnected from a water source.

Numerous maintenance issues were identified across settings including tall grass, protruding tree stumps, eroded asphalt, broken concrete, trash, metal, and glass hazards, uncovered sand in play areas unprotected from animals and insects, and vehicles parked on play surfaces. None of the playgrounds featured posted safety rules or emergency contact information; however, a few had signs prohibiting use during non-school hours.

Unintentional injuries are likely due to inadequate width and depth of fall zones around and beneath playground structures, limited space for movement between different structures (climbers, swings, seesaws, etc.), and lack of guardrails and protective barriers to prevent falls. Few play areas featured secure fencing to prevent young children from wandering and entrance of uninvited visitors and animals.
Students observed that electrical appliances were not securely covered.

Equipment hazards included unsafe surfacing below play equipment (earth, grass or loose fill material of gravel and stone), and entanglement hazards (uncovered hardware connectors). Students identified trip and fall hazards such as exposed anchors, loose ropes, frayed cables, warped and cracked wood, and rusted and unmoving parts.

Unfortunately, few playgrounds in 12 cities and 1 county received high ratings that reflect compliance with recommended guidelines for equipment, installation, and maintenance. Desirable features included:

- at least one accessible route from the perimeter to all equipment and play areas

- $\quad$ shade structures covering exposed climbers and sand pits

- secure fencing to separate children at-play from streets and parking areas

- soft surface fall zone beneath and six feet around playground equipment

- connectors are not entanglement hazards

- moving parts of equipment are covered and in good repair

- playground equipment is anchored

- equipment is free from broken, missing, damaged or loose parts

- no sharp or jagged edges

- grounds are clean, well-drained and wellmaintained without visible safety hazards

Student and faculty mentors photographed desirable playground features to use during faculty and staff professional development programs. Photos were used in conjunction with assessment data to advocate for maintenance improvements.

\section{School and Community Gymnasiums}

A majority of school and community gymnasiums also failed to meet recommended guidelines. Calculated means of dichotomous data revealed four most frequent safety hazards in school and community gymnasiums across 45 sites: Item \#24 - Equipment for the physical education program is developmentally 
appropriate and in good repair (mean 0.42); Item \#29 - First aid kit is stocked and readily available to use for student injuries (mean 0.66); Item \#5 - The space for physical activity is large enough to accommodate all students of a class moving at the same time (mean 0.75); \& Item \#10 - Floors of dressing rooms are pitched; drains are covered and cleared of debris (mean $0.75)$.

Qualitative data revealed that most gymnasiums lacked adapted equipment for students with disabilities. Student raters could not find first aid supplies and instructions for use. In specific settings, electrical fixtures were uncovered and posed a safety hazard as with the playground. Water fountains were dirty or non-functioning. Maintenance concerns included broken ceiling tiles and windows, exposed non-insulated hot water pipes, stopped drains in dressing areas, insect infestation, chipped and peeling paint, and water leaks. Designated fire exits were blocked by athletic equipment and supplies. Overall, rules for inclement weather were infrequently posted, a concern in a coastal state often beset by severe weather.

\section{Lessons Learned and Recommendations}

The collaboration between a university school of education, college of nursing, and public school system in the southeastern U.S. yielded several outcomes including development of two instruments, "Assessment of an Outdoor Elementary School Playground" and "Assessment of a School Gymnasium." Developers believe these brief instruments are a viable option for school, park and recreation professionals and community advocates with limited funds to purchase safety checklists and consultation for staff training. Data were used to recommend improvements to school, city, and park administrators. The town mayor where the project was conducted formed a partnership with a regional medical center to renovate a city park, which now features a paved walking trail and fitness stations accessible to children and those with mobility impairments. The school board scheduled overdue maintenance for playgrounds in one community.
Plans include continued work to estimate instrument reliability and validity before use in a research study. Authors learned that neither instrument universally applies to all settings (public schools and parks, as well as commercial playgrounds). Differences in resources to purchase, install, and maintain facilities for physical activity may exist across urban and rural communities. Construction and safety standards need to be widely communicated among professional and governmental organizations.

Teachers, parents, students, and community residents can learn to assess local playgrounds and gymnasiums and use data to plan improvements. It is necessary to provide free or low-cost assessment tools. Shared events, such as community build or clean-up days, are opportunities to increase collective responsibility for youth health and fitness. Parent-teacher organizations may plan fundraisers to acquire new park property and purchase equipment. Community business and industry partners may contribute expertise and funding.

School wellness teams may use data to establish a need, and then contact local community foundations to apply for funding. National initiatives, such as Project FIT America (http://projectfitamerica.org/), KaBOOM! (http: //www.kaboom.org/), the Shade Foundation of America (http://www.shadefoundation.org/stru ctures.php), and Lowe's Toolbox for Education (http://www.toolbox foreducation .com/) provide small grants to promote active, fit and healthy youth. Funds may be used for teacher and parent training, site preparation, purchasing equipment, and program evaluation.

\section{Acknowledgement}

Authors gratefully acknowledge support for Selma NEWS received from the University of Alabama at Birmingham School of Education, Alabama State Department of Education, Child Caring Foundation, and Alabama Department of Agriculture and Industries in the United States. 
References

Azar, B. (2002, March). It's more than fun and games. Monitor on Psychology, 33(3). Retrieved December 28, 2007, from http://www.apa.org/monitor/mar02/morefun.html

Centers for Disease Control and Prevention, National Center for Injury Prevention and Control, Division of Unintentional Injury Prevention. (2007, July 5). Playground injuries: Fact sheet. Retrieved December 15, 2007, from www.cdc.gov/ncipc/factsheets/playgr.htm

Cradock, A.L., Kawachi, I., Colditz, G.A., Hannon, C., Melly, S.J., Weicha, J.L., \& Gortmaker, S.L. (2005). Playground safety and access in Boston neighborhoods. American Journal of Preventive Medicine, 28(4), 357-363.

Del Busto, D. (2005, Summer). The importance of physical education \& play for children. The Sport Supplement, 13(3). Retrieved December 28, 2007, from http://www.thesportjournal. org/sport-supplement/vol13no3/04_physical.asp

Frost, J.L. \& Drescher, N.L. (2000). ACEI speaks: A parent's guide to playground safety. Retrieved December 15, 2007, from http://acei.org/playsafe.htm

Geiger, B.F. (2005a, November 10). Assessment of an outdoor elementary school playground. Available from Dr. Brian F. Geiger, University of Alabama at Birmingham, Room EB 209, $15303^{\text {rd }}$ Avenue South, Birmingham, AL 35294-1250.

Geiger, B.F. (2005b, November 10). Assessment of a school gymnasium. Available from Dr. Brian F. Geiger, University of Alabama at Birmingham, Room EB 209, $15303^{\text {rd }}$ Avenue South, Birmingham, AL 35294-1250.

Geiger, B.F., Sims, S.K., Evans, R., Roy, J., Werner, K.A., Prier, M., Cochrane, K., Fulmore, J.S., Dawson, V.L., Kirkpatrick, S. \& Brown, D. (2009). Responses of health and physical educators to overweight children in Alabama. Health Promotion Practice, 10(1), 111-118.

Geiger, B.F. \& Werner, K.A. (2009). A guided walking trail to explore the Martin Luther King, Jr. National Voting Rights Walk and Selma antebellum historic district. International Journal of Heritage Studies, 15(5).

KaBoom! (n.d.). The importance of playspaces: Why play. Retrieved December 28, 2007, from http://www.kaboom.org/GettingStarted/WhyPlayMatters/tabid/68/Default.aspx

National Association for Sport and Physical Education. (2006, revised). National standards for sport coaches: Quality coaches, quality sports. Reston, VA: Author.

National Commission for Health Education Credentialing, Inc. (2008). Responsibilities and competencies of health educators. Retrieved August 01, 2009, from http://www.nchec.org/credentialing/responsibilities/\#Responsible1

National Program for Playground Safety. (2006a). S.A.F.E. - Age-appropriate design. Retrieved December 28, 2007, from http://www.playgroundsafety.org/safe/age.htm

National Program for Playground Safety. (2006b). America's playground: Safety report card. Retrieved December 15, 2007, from http://www.playgroundsafety.org/research/report_card_form.pdf

National Program for Playground Safety. (2006c). A quick checklist for parents. Retrieved December 15, 2007, from http://www.playgroundsafety.org/safety/checklist.htm

National Program for Playground Safety. (2002). Kid checker. Retrieved December 15, 2007 , from http://www.kidchecker.org/checker.htm

Sacks, J.J., Holt, K.W., Holmgreen, P., Colwell, Jr., L.S., \& Brown, Jr., J.M. (1990). Playground hazards in Atlanta child care centers. American Journal of Public Health, 80(8), 986-988. 
Suecoff, S.A., Avner, J.R., Chou, K.J., \& Crain, E.F. (1999). A comparison of New York City playground hazards in high- and low-income areas. Archives of Pediatric Adolescent Medicine, 153, 363-366.

Texas State Department of Health \& the National Safety Council. (n.d.). Poisonous plants and plant parts. Retrieved December 15, 2007, from http://aggie-horticulture.tamu.edu/plant answers/publications/poison/poison.html

U.S. Consumer Product Safety Commission. (2005). Outdoor home playground safety handbook. Pub. No. 324. Retrieved December 15, 2007, from http://www.cpsc.gov/cpscpub/pubs/ 324.pdf

U.S. Consumer Product Safety Commission. (2001). Is your home playground a safe place to play? Retrieved December 15, 2007, from http://www.cpsc.gov/cpscpub/pubs/pg1.pdf

U.S. Consumer Product Safety Commission, Office of Information and Public Affairs. (n.d.-a). Tips for public playground safety. Document \#324. Retrieved December 15, 2007, from http://www.cpsc.gov/CPSCPUB/PUBS/Playfct.pdf

U.S. Consumer Product Safety Commission. (n.d.-b). Prevent burns on hot metal playground equipment. Document \#5036. Retrieved December 15, 2007, from www.cpsc.gov/cpscpub/pubs/5036.pdf

U.S. Consumer Product Safety Commission. (n.d.-c). Never put children's climbing gyms on hard surfaces, indoors or outdoors. Document No. 5119. Retrieved December 15, 2007, from http://rubbercal.com/files/USCPSC_5119.pdf

U.S. Consumer Product Safety Commission. (n.d. -d). Public playground safety checklist. Retrieved December 15, 2007, from http://www.cpsc.gov/kids/kidsafety/plgdlist.pdf

U.S. Consumer Product Safety Commission. (n.d.-e). Handbook for public playground safety. Pub. No. 325. Retrieved December 15, 2007, from http://www.cpsc.gov/cpscpub/pubs/ 325.pdf

Vygotsky, L. (2002). Play and its role in the mental development of the child. Psychology and Marxism Internet Archive. Retrieved August 7, 2009, from http://www.marxists.org/archive/vygotsky/works/1933/play.htm

Author Information

*Brian F. Geiger, Ed.D., FAAHE

Health and Physical Education Programs,

Department of Human Studies, School of Education,

College of Arts and Sciences,

Center for Educational Accountability,

University of Alabama at Birmingham,

Room EB 207

1530 3rd Avenue South, Birmingham

AL 35294-1250

Telephone: (205) 934-2446

Facsimile: (205) 975-8040

Jane Roy, Ph.D.

Health and Physical Education Programs, Department of Human Studies, School of Education College of Arts and Sciences 
University of Alabama at Birmingham

Sandra K. Sims, Ph.D.

Health and Physical Education Programs,

Department of Human Studies, School of Education

College of Arts and Sciences

University of Alabama at Birmingham

Jason S. Fulmore, Ph.D.

Health and Physical Education Programs,

Center for Educational Accountability,

University of Alabama at Birmingham,

Karen A. Werner, Ph.D. ${ }^{3}$

Senior Evaluation Specialist

Oak Ridge Institute for Science and Education

* corresponding author 